\title{
Perseguindo fios da meada: pensamentos sobre hibridismo, musicalidade e tópicas
}

\author{
Acácio Piedade (UDESC, Florianópolis, SC) \\ acaciopiedade@gmail.com
}

\begin{abstract}
Resumo: Discussão sobre os conceitos de hibridismo, musicalidade, fricção e fusão de musicalidades e tópicas da musicalidade brasileira. 0 objetivo é refletir sobre a questão da mudança e a transformação nos gêneros musicais, bem como a da permanência de elementos e figurações musicais que, por sua vez, carregam consigo nexos sócio-culturais e históricos que, de alguma forma, são experimentados pelos músicos e audiências. Tendo como foco questões da música brasileira, este artigo apresenta a busca de tópicas musicais ("brejeiro", "época-de-ouro" e "nordestina") como uma ferramenta para enfrentar o problema das transformações no mundo da música.
\end{abstract}

Palavras-chave: hibridismo; musicalidade; tópicas musicais; música brasileira.

\section{Pursuing clues to the puzzle: thoughts on hybridism, musicality and topics}

Abstract: Discussion about concepts such as hybridism, musicality, friction and fusion of musicalities, and the topics of the Brazilian musicality. It aims at reflecting on the question of the change and transformation in musical genres, as much as that of the permanence of musical elements and figurations that, in its turn, carry socio-cultural and historical connections that are somehow experienced by musicians and audiences. Focusing on questions of the Brazilian music, this article presents the search for musical traces called topics ("brejeiro" [maliciously smart ], "época-de-ouro" [good times], and "nordestina" [northeasterly Brazilian]) as a tool to face the problem of the transformations in the world of music.

Keywords: hybridism; musicality; musical topics; Brazilian music.

\section{1 - Hibridismo}

Fala-se muito de hibridismo nos estudos de música popular, principalmente no que tange à constituição e mudança nos gêneros e linguagens musicais. Gostaria de refletir sobre este conceito. Para os gregos antigos - tomemos este ponto como originário -, a hybris nomeava uma força excessiva que violava as leis naturais. Esta ideia foi sendo historicamente transformada e filtrada, primeiramente pelos romanos antigos e depois pela cultura europeia dos primeiros séculos, passando pelo sentido de transgressão de parentesco em direção àquele do orgulho que rompe com a lei moral. No século XIX, Mendel consolidou o uso de termo híbrido para nomear organismos criados artificialmente a partir do cruzamento de espécies naturais. Trata-se da criação de um novo corpo: nos termos da genética atual, um novo DNA. No campo das humanidades, o termo hibridismo aparece como metáfora biológica já em escritos oitocentistas sobre raças humanas. 0 paradigma evolucionista imperava no pensamento antropológico, e temos aqui não apenas o uso do termo hibridismo em um contexto que hoje entendemos como racista, como também a ideia de que o hibridismo, aplicado ao mundo social, porta um componente ideológico, uma remissão à questão de poder, seja isto consciente ou subliminarmente. Este vínculo congênito tem sido re- 
velado especialmente nos estudos do pós-colonialismo (BHABHA, 1994). Tomando os processos de mudança e fertilização cruzada como legítimos agentes das forças de poder no mundo, o discurso anti-essencialista do hibridismo permeia várias teorias da globalização há pelo menos duas décadas (ver CANCLINI, 1995).

Atualmente, aparentemente estamos longe dos sentidos antigos de hybris, nós que habitamos o mundo da velocidade e da mudança: o excesso e a transformação parecem ter-se instaurado no calor da sociedade ocidental e ai serem tomados como processos naturais. Digo "calor", aqui, no sentido levi-straussiano de sociedades quentes (LÉVI-STRAUSS, 1989), ou seja, aquelas que concebem o devir como História, dirigindo-se para o futuro através do progresso e da transformação tecnológica. Note-se que, para LATOUR, a modernidade é iniciada pela separação entre mundo social, mundo natural e religioso, e a própria palavra "moderno" implica em uma mediação entre estes mundos, onde há misturas de gêneros completamente novas, os "híbridos de natureza e cultura" (LATOUR, 1994). 0 processo de hibridização seria, desta forma, congênito ao espírito moderno e à sociedade quente ocidental.

$\mathrm{Na}$ literatura das humanidades, as transformações da cultura e a criação de categorias híbridas não são entendidas como uma violação da natureza, nem como ato da soberba humana que se põe acima da moralidade, e nem sempre como processos que envolvem ideologias implícitas. No entanto, talvez um pouco de tudo isso esteja em jogo quando olhamos para os fenômenos cobertos pela metáfora do hibridismo no campo da cultura, e talvez possa haver laços com o sentido originário.

No contexto da temática do hibridismo na virada do séc. XX para o XXI, podemos perguntar: as teorias do hibridismo cultural anunciam este estado híbrido como uma nova roupa da cultura? A hibridez cultural depende do multiculturalismo? 0 hibridismo surge como uma consequência da modernidade? Muitas destas questões já se encontram bem trabalhadas na vasta literatura das ciências sociais a respeito ${ }^{1}$. Gostaria de pontuar aqui as seguintes questões: o corpo hibrido traz em si elementos divergentes que, uma vez incorporados, pacificamse mutuamente? Senão há uma paz, haveria ao menos uma lei social necessária para regular os elementos hibridizados, e então será que o corpo híbrido é regulado por um terceiro, que coloniza os elementos no processo de hibridização? Gostaria aqui de pensar estes pontos no campo da música.

De início, vamos identificar dois tipos de hibridismo: chamemos de hibridismo homeostático aquele que pressupõe o corpo híbrido como domesticado, equilibrado, onde há uma real fusão, ou seja, A deixa de ser $A$ enquanto tal e $\underline{B}$ deixa de ser $\underline{B}$ enquanto tal para que se encontrem em conjunção na construção de um novo corpo estável, $\underline{C}, 0$ híbrido; no outro tipo de hibridismo não há fusão, nem equilíbrio, $\underline{A}$ não pode deixar de ser $\underline{A}$, e nem $\underline{B}$ pode fazê- lo, ambos estando dispostos em um corpo que não é $\underline{C}$, mas $\underline{A B}$. Em $\underline{A B}$, é importante que $\underline{A}$ se mostre como $\underline{A}$ e que $\underline{B}$ se mostre como $B$. Mais propriamente, $A$ necessariamente se afirma enquanto $\underline{A}$ perante $\underline{B}$ e vice-versa. $A$ é contrastivo em relação a $B$ no corpo $A B$, cujo cerne é justamente esta dualidade. Se este corpo $\underline{A B}$, no qual a identidade de $\underline{A}$ e $\underline{B}$ se apresentam conjunta e contrastivamente, pode ser chamado de híbrido, então podemos falar aqui de um hibridismo contrastivo.

Assim, vamos considerar o hibridismo na música. Vamos falar de $\underline{A}$ e $\underline{B}$ em $\underline{A B}$ não como suas seções formais, mas como motivos ou frases específicas em modos determinados, progressões harmônicas típicas, ritmos padronizados, timbres denotativos, ou combinações de tudo isso em estruturas curtas. Creio que, ao menos na música, na maioria dos casos se trata do segundo tipo de hibridismo, o contrastivo, e é por isso mesmo que eu gostaria destacar a importância da retórica musical aqui. Em $\underline{A B}$, o elemento $\underline{A}$ está ali para ser ouvido enquanto $\underline{A}$, e o elemento $\underline{B}$ também se apresenta como $B$, para o ouvinte. Cada um deles tem um papel na expressão musical e por isso são criados para serem reconhecidos. Ou seja, na composição musical, tanto quanto na improvisação, a enunciação destes elementos é voltada para a audiência em busca de compreensão. Isto configura o viés expressivo, a necessidade de comunicação, a retórica por trás do hibridismo contrastivo. Vou retomar isto mais adiante.

Uma das limitações da abordagem acima é que ela é voltada para o objeto em si, mas talvez no campo da música o microscópio deva se tornar um macroscópio, pois o objeto, música, porta consigo necessariamente nexos sócioculturais e históricos cuja imbricação semântica com os sons torna difícil considerá-los exteriores. Ou seja, os fatos culturais que permeiam e constroem os gêneros musicais fazem parte do objeto tanto quanto os sons. Claro que podemos isolar os sons, criar partituras, observar os mecanismos musicais, analisar tecnicamente, trata-se de um passo fundamental no entendimento dos processos teóricos em música, mas no momento em que se pretende lançar um olhar compreensivo ${ }^{2}$, é necessário recompor a integridade do objeto. Nesta direção, vamos pensar a retórica por trás hibridismo através dos conceitos de musicalidade e de tópicas musicais.

\section{2 - Musicalidade}

Em estudos sobre o jazz brasileiro (PIEDADE 1997, 2003, 2005, 2010; PIEDADE \& BASTOS 2007), musicalidade é uma memória musical-cultural compartilhada constituída por um conjunto profundamente imbricado de elementos musicais e significações associadas. A musicalidade é desenvolvida e transmitida culturalmente em comunidades estáveis no seio das quais possibilita a comunicabilidade na performance e na audição musical. Vamos entender aqui comunidade no sentido de agrupamento social com valores compartilhados, como em BAUMAN (2003), seja este grupo territorializado ou não ${ }^{3}$. Qualquer grupo social é sujeito a permanentes transformações, daí que "estabilidade", aqui, significa uma duração historicamente ob- 
servável de um agrupamento, à qual se atribui significância em termos metodológicos.

Mais do que uma língua musical, portanto, musicalidade é uma audição-de-mundo que ativa um sistema musicalsimbólico através de um processo de experimentação e aprendizado que, por sua vez, enraiza profundamente esta forma de ordenar o mundo audivel no sujeito. No jazz brasileiro, chamado de pelos nativos de "música instrumental", há uma relação típica com o jazz norteamericano que é ao mesmo tempo de tensão e de síntese, de aproximação e de distanciamento. A forma como a musicalidade brasileira e a norte-americana se encontram no jazz brasileiro confere com a ideia de hibridismo contrastivo: as tópicas musicais presentes nos temas e improvisações estabelecem uma relação de fricção de musicalidades ${ }^{4}$. Esta revela a sua relação com discursos sobre imperialismo cultural norte-americano, identidade brasileira, globalização e regionalismo.

Entretanto, a musicalidade não é um sistema fechado e imutável. Um indivíduo pode tentar desenvolver seu ouvido musical em um outro sistema musical, e com isso ele está desenvolvendo uma outra musicalidade, o que significa o exercício de uma competência em uma pedagogia estética sonora particular. 0 que HOOD (1960) chamou de "bi-musicalidade" começou a apontar nesta direção. 0 que hoje se torna claro é que este processo de musicalização envolve decisões eminentemente sócio-culturais, e estas são tomadas ainda que inconscientemente. Ou seja, um indivíduo pode buscar tornar-se nativo de uma comunidade musical através de uma autodeterminação em absorver aquela forma particular de musicalidade, mas este afinco necessariamente inclui elementos simbólicos que coordenam os nexos sócio-culturais da musicalidade: estes fazem parte do pacote absorvido pelo estudante. Por isso, a musicalidade não está no indivíduo, não depende de sua habilidade, mas se encontra sim na comunidade e seus gêneros musicais, que estão em permanente trânsito e transformação.

Falamos de hibridismo contrastivo e fricção de musicalidades, mas e o hibridismo homeostático na música, seria possível? Esta situação de contraste ou conflito poderia ser um periodo transitório que tenderia à construção de uma estabilidade de gênero? E este poderia reiniciar 0 ciclo entrando em fricção com outro conjunto? A fricção pode ser vista como uma fase de um processo que leva a um estado de homeostase que se poderia chamar de "fusão de musicalidades". Como a musicalidade é uma memória, as musicalidades constituintes da fusão não mais se farão distintas no mundo nativo e não haverá, portanto, nenhuma fricção. Para que esta fusão pudesse ocorrer seria necessário que os elementos sócio-culturais inerentes às musicalidades, referentes a aspectos existentes no mundo social das comunidades musicais, também entrassem, de alguma forma, em alguma espécie de diluição. 0 conflito existente no contraste haveria de ser apaziguado por um consenso ou acordo: este seria eminentemente simbólico, pois a desigualdade é congênita ao mundo social. Sobretudo, é o tempo histórico que possibilita a fusão. Creio que este movimento de fusão é permanente na história da música e que é justamente este processo que está na base da invenção das tradições (HOBSBAWM \& RANGER, 1983): uma tradição é sempre entendida pelos nativos como realidade homeostática, porém há na sua origem um acordo esquecido, um contraste diluído. Há que haver um esquecimento do contraste inicial: a tradição é $\underline{A}$ que, na verdade, é um $\underline{C}$, ou seja, um $\underline{A B}$. Se não houvesse este tipo de esquecimento, a humanidade não poderia ouvir música, pois toda a multiplicidade imemorial de gêneros e elementos que fundam as músicas se exporia diante de nossos ouvidos.

0 esquecimento ou a naturalização da diferença são, de fato, processos congênitos da memória e, portanto, da história (ver RICOEUR, 2000; ZUMTHOR, 1997). Sobretudo, sem o esquecimento de que o tradicional, o gênero "raiz", é na verdade um híbrido, produto da circulação transnacional das ideias musicais, as comunidades não poderiam chamar alguma música de tradicionalmente sua. 0 tradicional é transnacional por natureza. Na história da música, há o constante desenrolar de um processo de fricção e fusão de musicalidades: tópicas, estilos e gêneros contrastivos são reunidos e diluídos em outros de sua espécie, e estes, por sua vez, avançam, formando novas tópicas, estilos, gêneros, unidades com identidade própria que podem vir a se fundir.

0 que eu gostaria de destacar é que, quando se fala de "influência", trata-se de reconhecer as musicalidades constituintes de um estilo, seja pela análise das mais evidentes, contrastivas, ou por uma arqueologia que revela mesmo no mais auto-regulado dos estilos uma diversidade de vínculos distantes. Por exemplo, no caso da linguagem musical de J. S. Bach, já é bem conhecido o fato de que este compositor estudou muito a música barroca italiana, conhecendo profundamente os estilos de Frescobaldi, Vivaldi, Corelli, e formas como concerto e ricercare (ver WOLFF et al, 2010). Para o ouvinte regular contemporâneo, entretanto, este eco se encontra fundido na musicalidade bachiana, juntamente com outras musicalidades que constituem seu estilo. Além disso, 0 estudo da integridade sócio-cultural das musicalidades nesta fusão pode revelar aspectos sociais, políticos e religiosos importantes para uma compreensão mais funda da música, da pessoa e do tempo de Bach: nexos ativos, reconhecidos na sua época, como as figuras de retórica, e mesmo outros mais subliminares, relacionados a questões políticas e sociais (MCCLARY, 1987). Outro exemplo é a presença da modinha na música brasileira, já exaustivamente estudada (VEIGA, 1998). Dada como gênero atualmente extinto, a modinha teve grande sucesso no Brasil a partir do século XIX, principalmente na corte (ver MONTEIRO, 2008), e penetrou na musicalidade brasileira de forma definitiva, sobrevivendo através de tópicas tremendamente ativas em vários repertórios da música brasileira ${ }^{5}$ : trata-se de uma parte fundamental do universo de tópicas época-de-ouro (adiante tratarei mais disso). 
Pode-se mencionar também a musicalidade caribenha no samba-canção, via bolero (ARAÚJO, 1999), que marcou uma parte importante da bossa nova: tópicas caribenhas estão vivas em diversos repertórios brasileiros, especialmente a batida de bongô. Estes casos podem ser considerados exemplos de fusão de musicalidades, pois aparentemente não há conflito inerente: ao contrário, parece ter havido um consenso tácito na geração destes gêneros que lançou para o esquecimento a multiplicidade original (que, no entanto, não deixa de existir e de se revelar seja no discurso do senso comum quanto na análise). Haveria centenas de exemplos como estes a dar: de fato, creio que este processo de fricção e fusão de musicalidades se dá constantemente em vários sistemas musicais do mundo todo. Acho que o cenário das musicalidades, como aquele das culturas, é de permanente encontro, intercâmbio e mudança ocorrendo em diferentes intensidades e velocidades. Há setores da música mundial que são mais propensos às mudanças rápidas, enquanto outras regiões musicais trabalham mais pela permanência. Ou seja, usando novamente o conceito de Lévi-Strauss, creio que há musicalidades frias e quentes.
Muitas vezes se utiliza o conceito de hibridismo para tratar da imbricação de elementos estilísticos que sintetizam uma obra ou gênero musical. Esta mistura de elementos é normalmente positivada, tomada como índice de complexidade ou sofisticação. Pressupõe-se assim a possibilidade de sintese, de fusão, mas esta nem sempre implica em unidade, ainda que a consciência perceptiva tenda de início a tomar o corpo sonoro como uno e estável. Tenho trabalhado a noção de tópicas musicais da musicalidade brasileira para tentar identificar e isolar estes elementos $\underline{A}$ e $\underline{B}$ que são utilizados em largo espectro em diversos repertórios da música brasileira, com a particularidade de se fazerem contrastivos entre si a ponto de se destacarem no tecido musical e de portarem remissões significativas a elementos culturais. Estes elementos, creio, podem ser agrupados em um número reduzido de categorias gerais, os universos de tópicas. Entre os universos de tópicas mais centrais da musicalidade brasileira, há as tópicas "brejeiro", "épocade-ouro" e "nordestinas". Abaixo vou apresentar um resumo destes três universos de tópicas, conforme exposto em PIEDADE (2007) e PIEDADE \& BASTOS (2007).

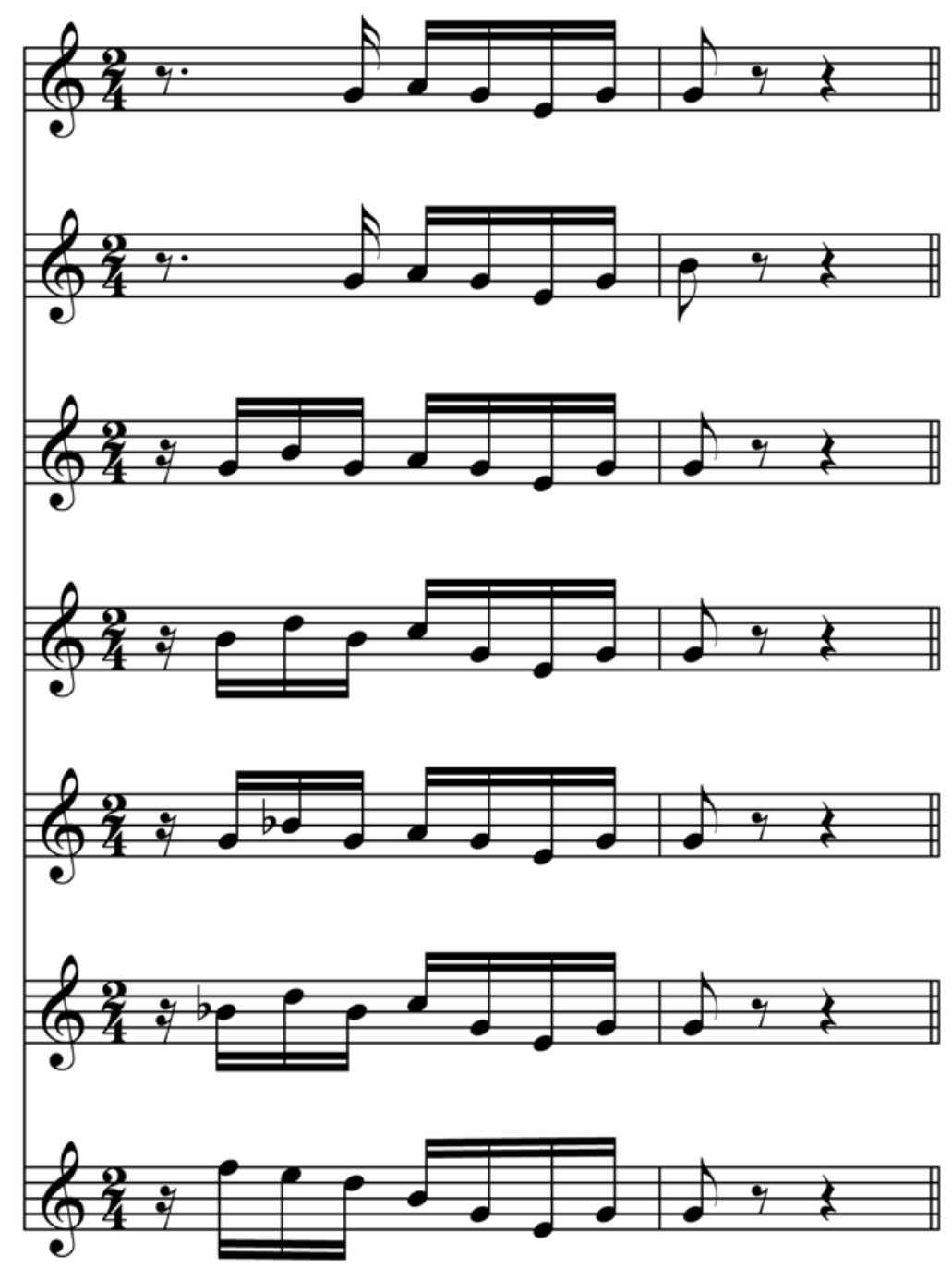

Ex.1 - Cadências "nordestinas" em Sol. 


\section{3 - Tópicas}

Desde cedo, na literatura, o nordeste se apresentou como Brasil profundo, e a musicalidade nordestina levou a um universo de tópicas muito importante na música brasileira. Não basta ser dórico ou mixolídio, com ou sem $4^{\text {a }}$ aumentada, para levantar uma evocação do nordeste: é preciso que estas alturas apareçam em figurações específicas, como a cadência nordestina. No Ex.1, acima, encontra-se a cadência nordestina em Sol com variações adequadas ao dórico e ao mixolídio.

As tópicas nordestinas são peças-chave do repertório do baião, e dali migraram para uma parcela enorme dos gêneros musicais brasileiros. Criou-se o mito do nordeste musical, o mistério do nordeste profundo, que foi fonte exuberante para compositores nacionalistas e continua sendo, passando por Elomar, o movimento armorial, o jazz brasileiro e muitas outras paragens.

0 brejeiro é aquele estilo em que as figurações aparecem transformadas por subversões, brincadeiras, desafios, exibindo e exigindo audácia e virtuosismo, mas tudo isto de forma organizada, elegante, altiva, por vezes sedutora, maliciosa. Trata-se de um gesto eminentemente individualista: o indivíduo se destaca da massa, como que zombando de sua regularidade e previsibilidade monótona. 0 brejeiro está profundamente relacionado a alguns gêneros, como o choro, ali transparecendo originariamente no papel do flautista dos grupos formados no final do século XIX, que usualmente desafiava seus acompanhantes com frases irregulares e rápidas, exibindo algum virtuosismo instrumental. 0 brejeiro na musicalidade brasileira se manifesta no gingado da capoeira: o corpo faz gestos surpreendentes, o oponente toma uma rasteira e cai. 0 brejeiro se consolida na figura mítica do malandro, que ginga a sociedade com seus pés, desafia a legalidade com sua esperteza. Ou seja, desloca o tempo forte e o acentua no fraco, realiza a "quebrada", ataca uma nota com uma ornamentação cromática que causa a impressão de erro, mas que revela a precisão de uma transformação brejeira. Vou apresentar alguns exemplos, alguns destes já mencionados em BASTOS (2008), onde há vários exemplos de tópicas no choro e no jazz brasileiro. Um exemplo é o bem conhecido deslocamento rítmico da segunda parte de Lamentos, de Pixinguinha, conforme mostra o Ex.2:

A métrica do choro é tipicamente bastante regular, de modo que estes deslocamentos se destacam como figurações bem marcantes. No Ex.3 temos outro deslocamento rítmico brejeiro que se dá no início do choro Um a Zero, de Pixinguinha.

É interessante notar que esta melodia foi escrita para flauta, de modo que o trecho remete ao canto insistente de um pássaro que atravessa a música. 0 brejeiro também se apresenta na composição Joaquim Virou Padre, de Pixinguinha, nas suas subidas e descidas cromáticas surpreendentes para os anos 20 e que lembram a irreverência de Thelonius Monk em Well You Needn't, de 1957. As tópicas brejeiro aparecem também no tom lascivo e debochado de algumas melodias que vão ser importantes na gafieira, notadamente nos solos de trombone, mas já no Trombone atrevido, também de Pixinguinha, as notas repetidas evocam esse espirito. No choro Na Glória, de Ary dos Santos

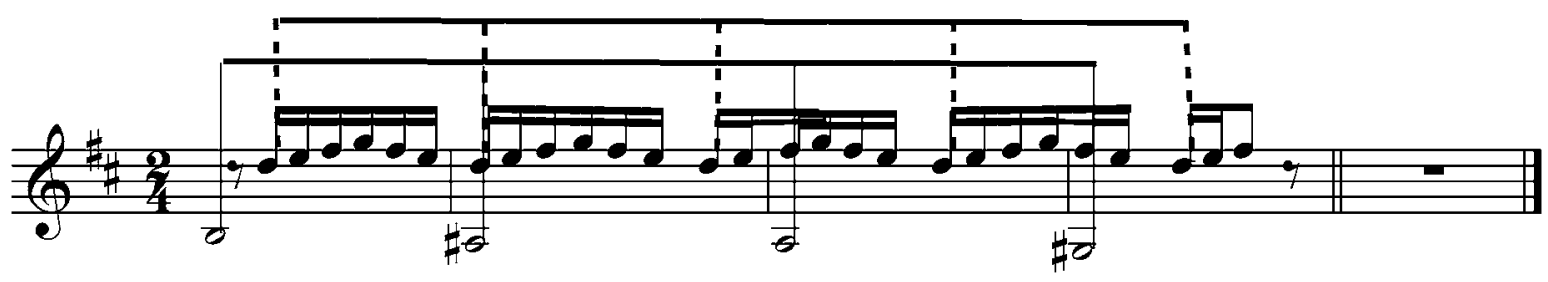

Ex.2 - Deslocamento "brejeiro" em Lamentos.

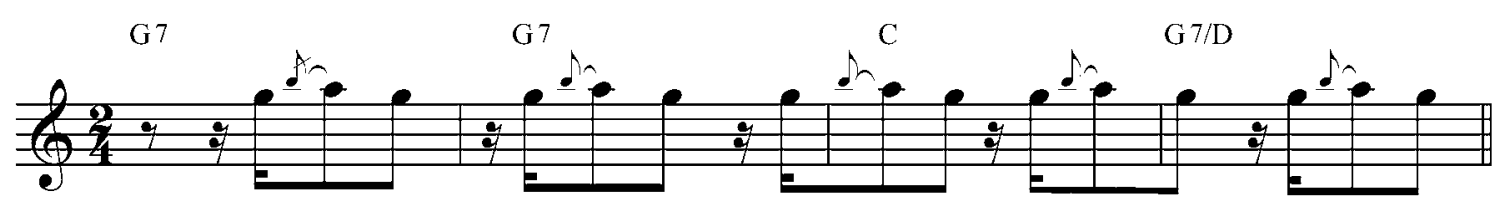

Ex.3 - Deslocamento "brejeiro" em Um a Zero. 


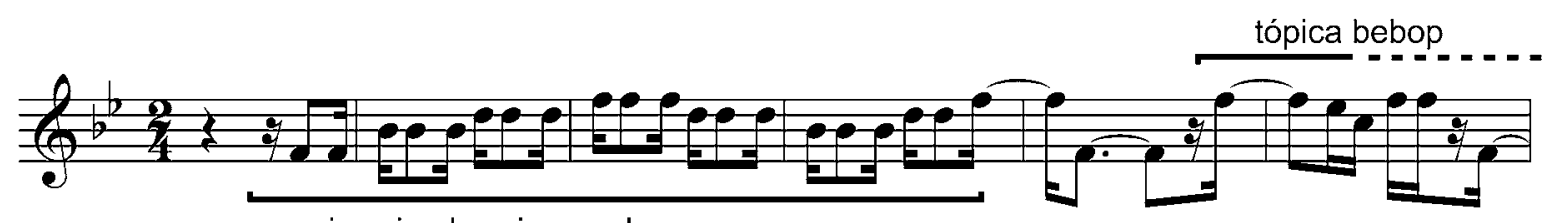

arpejos simples sincopados

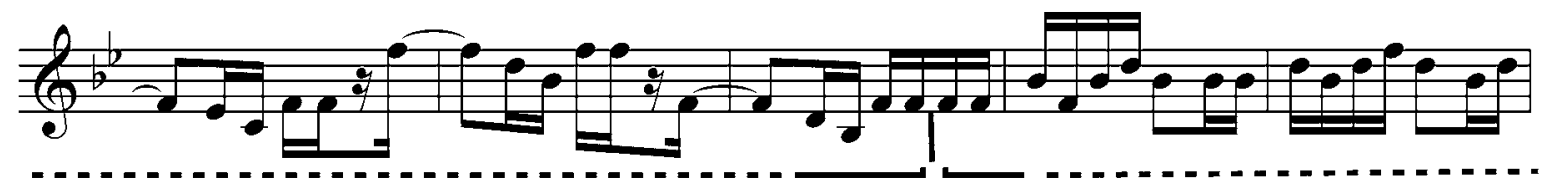

citação direta: Hino do Expedicionário

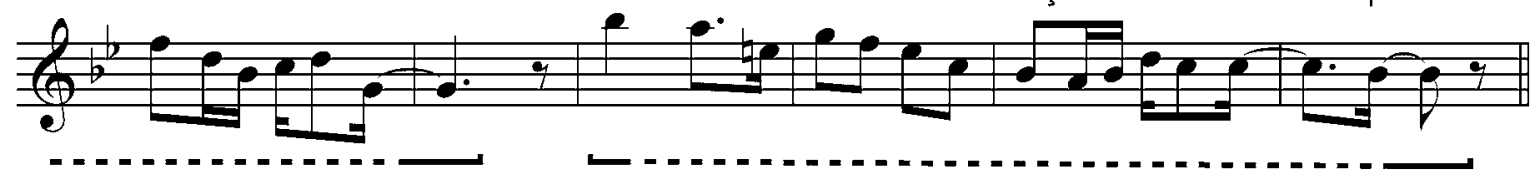

citação direta: Marcha Nupcial

Ex.4 - Tópicas "brejeiro" na terceira seção de Na Glória.

e Raul de Barros, esta tópica brejeiro aparece na terceira seção. Esta parte se inicia com arpejos sincopados de Si bemol, lembrando um toque militar carnavalizado, e em seguida aparece uma tópica bebop (ver PIEDADE 1997, 2003; PIEDADE \& BASTOS, 2007) que, aliás, muitas vezes é executada com swing de jazz. Em seguida, citações diretas brejeiramente evocam o militar, com o hino do expedicionário e a cerimônia de casamento, com trecho da marcha nupcial de Mendelssohn. Vejamos esta densa passagem no Ex.4, acima.

A citação direta é mais do que simplesmente uma paródia, é uma "citação em contexto" (PIEDADE, 2005): típica desta do espirito brejeiro, trata-se de encaixar um tema na estrutura da peça que está sendo executada um tema, de forma que este outro tema seja reconhecido pela audiência. Há um contexto específico em toque: este encaixe envolve estratégia, perícia, malícia brejeira, e isto também deve ser reconhecido pela audiência. Eis aqui uma situação típica da retórica. Ao mesmo tempo, o tema citado porta uma significação própria que, injetada no tecido que lhe acolheu, cria uma conotação implícita. Neste caso, há claramente uma paródia à rigidez militar, mas também uma referência aos Estados Unidos via tópica jazz, e por fim, o casamento, talvez índices que apontam para o quartel e a igreja do bairro. De qualquer forma, a audiência ela mesma costura estas significações, ainda que tacitamente.

0 universo de tópicas época-de-ouro inclui floreios melódicos das antigas modinhas, polcas, valsas e serestas brasileiras. A execução de traços destas melodias ornamentadas evoca a simplicidade, a singeleza e o lirismo do Brasil antigo. Este Brasil profundo se expressa em floreios melódicos em certas frases, padrões harmônicos, ornamentação típica (muitas apojaturas e grupetos) que estão fortemente presentes nas modinhas, polcas, no choro e, a partir daí, em vários outros repertórios de música brasileira, e mesmo em segmentos de obras de um estilo completamente diferente do ambiente época-de-ouro. Para ficar com Pixinguinha, o Ex.5 apresenta um trecho da valsa Rosa com várias tópicas época-de-ouro, como 0 grupeto, o volteio e as apojaturas 6-5 e 2-1.

Este tipo de figuração vem adentrando a musicalidade brasileira aos poucos ao longo do século de XIX e se consolida na obra de compositores como Ernesto Nazareth, que se inspirava no lirismo romântico europeu de compositores como Chopin (MACHADO, 2007). Surge em modas, polcas, maxixes, sambas, marchas-rancho, obras eruditas de compositores como Villa-Lobos, Camargo Guarnieri, Francisco Mignone, canções de Chico Buarque, temas de Hermeto Pascoal, improvisos de Toninho Horta, enfim, é uma faceta viva da musicalidade brasileira que traz como nexo simbólico a nostalgia, a flecha que aponta para o passado, o interno, a tradição, a raiz. Como veremos adiante, trata-se de uma ficção absolutamente necessária para que haja vínculo social. Estes universos de tópicas flutuam acima da divisão entre o erudito e o popular, em uma esfera onde, articulados entre si e com outras musicalidades que surgem, são discursos fundamentais para imaginar a música brasileira.

Gostaria de comentar aqui um aspecto das tópicas época-de-ouro: é o conjunto de tópicas "de banda". Um dos nós da musicalidade brasileira encontra um nexo nas bandas militares. A formação aparentemente chega ao Brasil com a corte de D. João VI (BINDER, 2006) , as ban- 

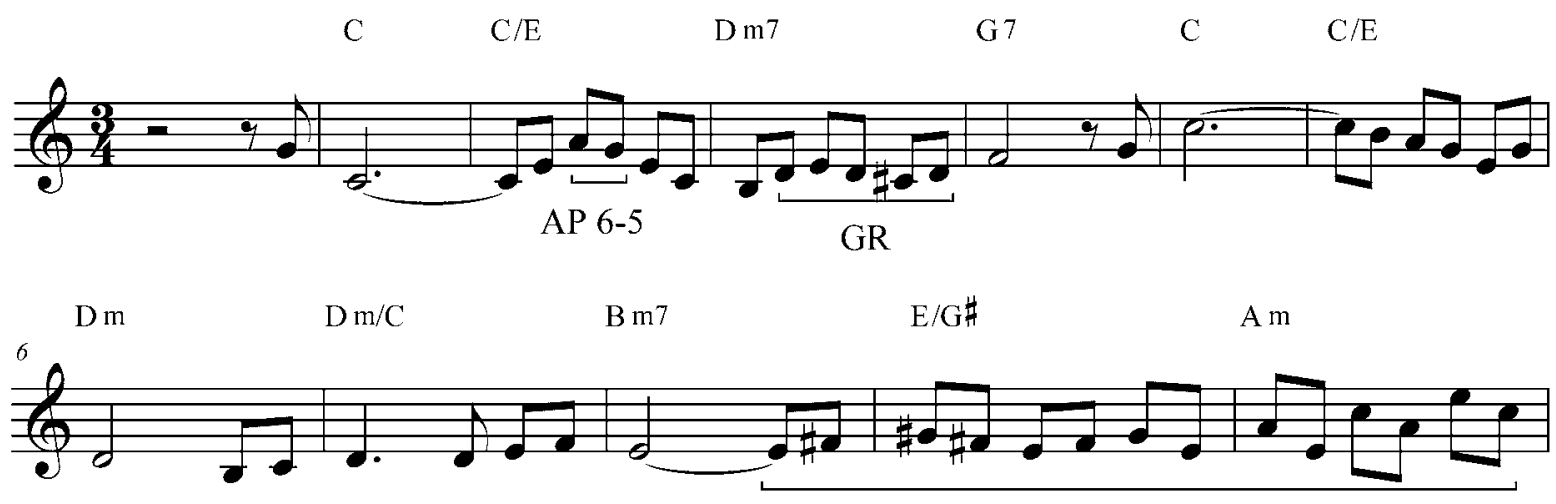

$\mathrm{A} 7 / \mathrm{C}$

$\mathrm{Dm}$

$\mathrm{D} \mathrm{m} / \mathrm{F}$

G 7sus 4

G7

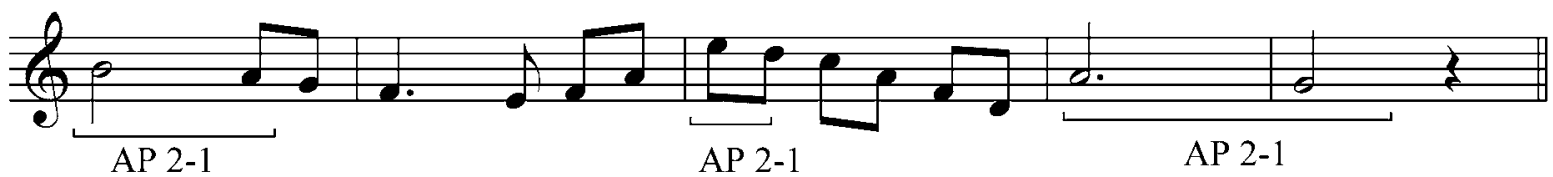

Ex.5 - Tópicas "época-de-ouro" em Rosa.

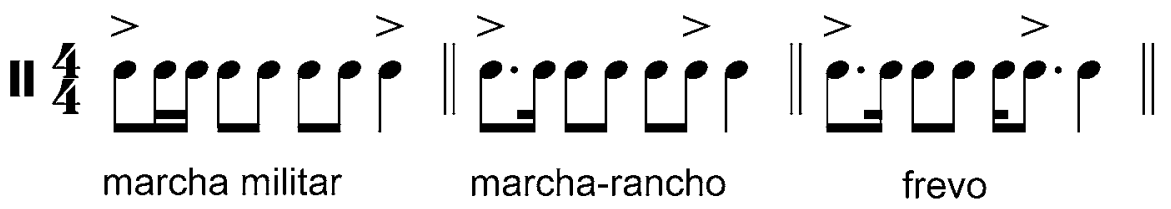

Ex.6 - Deslocamentos de acentuação na marcha, marcha-rancho e frevo.

das militares formaram um modelo que a sociedade civil podia reproduzir, e assim foram criadas sociedades musicais em vários municípios brasileiros, chamadas de "Lira", "Filarmônica", "Orfeão", "Associação" ou "Corporação", ou mesmo "Banda". Os trajes militares e a formação típica se mantiveram, configurando quase que grupos "travestidos" de soldados: havia nas bandas civis um éthos militar (BINDER, 2006, p.77-82). Este é um aspecto importante: do universo militar a sociedade deseja emular a ordem, a utopia de uma disciplina ausente na sociedade. A obediência às regras espraia-se na obediência ao maestro, a banda funcionando como alegoria da sociedade ideal. 0 lugar da banda é o coração da cidade, o coreto da praça principal, onde se encontra também a igreja matriz, e aos domingos se desenrola o ritual de uma sociedade perfeita, simples, ordenada, religiosa. Estes nexos ecoam no imaginário nativo quando as tópicas "de banda" aparecem. A música da banda, por excelência, é a combinação do som dos sopros com a rítmica da marcha, o dobrado.

0 militar na musicalidade das bandas remete, portanto, à ordem, disciplina, à perfeição do mundo social, e no frevo e marcha-rancho, à sua subversão carnavalizada pela sin- copa. 0 Ex.6, acima, traz um esquema simplificado destas relações, sobra as quais continuarei tratando adiante.

0 éthos militar atravessa estes gêneros não apenas em termos rítmicos, mas como uma musicalidade plena. Em todos os casos, ele porta traços de um antigo símbolo de alta classe: as bandas tocavam em festas da nobreza, em grandes recepções e cerimônias oficiais da corte imperial, os "rituais de monarquia" (como fala BINDER, 2006, p.90). Uma música "elevada" para ocasiões "elevadas", a força do metal aponta para a altivez, o vigor do Estado. Estes nexos, juntamente com a nostalgia típica do universo época-deouro, estão presentes na realidade musical das tópicas de banda: quando elas soam, soa também a doçura passageira do vigor juvenil e da utopia de transformação social. Como disse Chico Buarque na sua famosa canção, "tudo tomou seu lugar depois que a banda passou".

Na capital do Brasil no início do século $X X$, a musicalidade das bandas vai influenciar a formação do mundo do carnaval com o surgimento da "marchinha": a marcha-rancho. Pode-se dizer que ela mesma é um fruto hibrido: de um lado, a ênfase melodiosa legato típica das tópicas de se- 
resta e modinha e, de outro, o pulso bem marcado da rítmica das tópicas de banda. Nesta mistura musical e sóciocultural, nesta fusão de musicalidades, anseios sociais são tratados de maneira ritualizada (ver ARAÚJ0 et al, 2005).

No Recife, a aceleração do dobrado e sua fusão com outras musicalidades geraram o frevo, que efetiva uma espécie de carnavalização da musicalidade das bandas civis através das tópicas brejeiro. Quero dizer, o frevo, além do andamento rápido, traz figurações melódicas de grande agilidade, terminações acentuadas em tempo fraco, tipicamente instrumentais. Há no frevo uma transgressão do militar, um espírito guerreiro (ARAÚJO, 1997) que pode remeter a um nexo afro-brasileiro ou indígena. De início música instrumental (SUASSUNA et al, 1997, p.223), o frevo foi se transformando em dança, carnaval típico, frevo-canção e gênero musical estável na música brasileira. No entanto, no frevo ainda sobrevivem os pilares da marcha militar, nele ainda está ativo o nexo aerofônico com a musicalidade das bandas. Por isso, além do universo brejeiro, o gênero frevo partilha do universo de tópicas época-de-ouro. Entre os compositores atuais que cultivam tópicas de banda, especialmente via frevo, se encontram Hermeto Pascoal, Egberto Gismonti e Marlos Nobre.

\section{4 - Considerações Finais}

0 que eu estou tentando mostrar com estes exemplos é que o conceito de hibridismo nos estudos musicais funciona em uma camada tal que muitas vezes oculta um processo interior e anterior cuja investigação tem, a meu ver, bom rendimento através da musicalidade e do ensejo retórico implícito nestes gêneros. 0 termo hibridismo ganhou muito peso nos estudos literários e humanidades a partir de BAKHTIN (2008), porém, com a crítica cultural dos anos 70, os estudos do pós-colonialismo (BHABHA, 1994) impingiram na ideia de hibridismo seu necessário caráter ideológico que, apesar de indubitavelmente importante, muitas vezes simplesmente não é o caso nos estudos musicais.

0 debate sobre transformações e mudanças no universo da música é, em geral, tratado através do típico discurso das "influências", que acaba esterilizando processos cuja pertinência excede $o$ indivíduo e abrange a comunidade ou a cultura. Se a musicologia contemporânea tem se debruçado intensivamente sobre esta abrangência sócio-cultural das músicas (ver ARAÚJO et al, 2008; CLAYTON et al, 2003; STOBART, 2008; WILLIAMS, 2007), ao mesmo tempo há um desvio de olhar do texto musical, desvio que é herdeiro da velha crítica kermaniana ao formalismo da análise musical (KERMAN, 1987; ver COOK \& EVERIST, 2001). Para mim, uma forma de superar estes dilemas é analisar a mecânica do hibridismo através da musicalidade e das tópicas musicais, buscando recompor o significado a partir do ouvido e da análise musical e através de uma hermenêutica sócio-cultural. Entretanto, tal tarefa se torna cada vez mais complexa no mundo atual devido ao constante armazenamento e disponibilização de repertórios musicais, que infla e gera a imensa diversidade da música composta, tocada e ouvida hoje em dia, bem como devido ao fluxo das culturas mundiais em aceleração aparentemente irrefreável.

0 cenário mundial das músicas é estruturado por uma assimetria de centro e periferia, sendo que o fluxo cultural torna a periferia mais receptora de bens materiais ou simbólicos emanados a partir do centro, embora o fluxo contrário exista, aliás, sob a vigência de um sistema de propriedade bastante desigual (MALM, 2008). Segundo HANNERZ (1991) isto faz parte de um processo de homogeneização global da cultura que pode levar a duas possibilidades: uma é a "saturação", na qual o fluxo de influência transnacional seria tal que tomaria completamente a sensibilidade de uma cultura periférica, tornando-a cada vez mais indistinta em relação ao centro. É a versão global da ideia de assimilação, ou integração. Outra tendência é o que este autor chama de "maturação", onde as culturas periféricas poderiam colonizar este fluxo através de processos como a criolização, hibridismo, sincretismo, entre outros, o que acabaria por dissolver a polarização centro-periferia nos fluxos culturais. Não compartilho desta utopia de dissolução da polarização global, mas acredito, como este autor, que a cultura é ela mesma uma virtualidade em fluxo (ver HANNERZ, 1997). Ou seja, a cultura é um fluxo, seu aspecto estável decorre da necessidade de criação de tradições e territórios particulares com os quais um grupo se identifica: é a necessidade humana de pertencimento a um grupo limitado, contrastivo em relação a outros que cria a cultura. A música é um fenômeno fundamental neste processo, mas as músicas também são fluxos, tramados ao calor da história. Gêneros, estilos, motivos, frases, harmonias que se atravessam formando novas combinações: o hibridismo é um processo congênito e inevitável na música. Através das tópicas, como elas são cristalizações estáveis destes conteúdos, talvez seja possivel perseguir algumas linhas que costuram os tecidos mutantes que compõem as músicas no século $X X I$. 


\section{Referências}

AGAWU, V. Kofi. Playing with signs: a semiotic interpretation of classic music. Princeton: Princeton University Press, 1991. ARAÚJO, Rita de Cássia Barbosa de. Carnaval do Recife: a alegria guerreira. Estudos Avançados, vol.11, n.29, 1997, p.203-216. ARAÚJO, Samuel. The Politics of Passion: The Impact of Bolero on Brazilian Musical Expressions. Yearbook for Traditional Music, Vol. 31, 1999, p.42-56.

ARAÚJO, Samuel et al. Entre palcos, ruas e salões: processos de circularidade cultural na música dos ranchos carnavalescos do Rio de Janeiro (1890-1930). Em Pauta, 16, 26, 2005, p.73-94.

ARAÚJO, Samuel et al (eds) Música em Debate - perspectivas interdisciplinares. Rio de Janeiro: Mauad X/Faperj, 2008.

BAKHTIN, Mikhail. A Cultura Popular na Idade Média e no Renascimento: o contexto de François Rabelais. São Paulo/ Brasilia: Hucitec/Editora Unb, 2008.

BARTH, Fredrik. Ethnic groups and boundaries: the social organization of culture difference. Prospect Heights, Illinois: Waveland Press, 1998.

BASTOS, Marina Beraldo. Tópicas na música popular brasileira: uma análise semiótica do choro e da música instrumental. Monografia de Conclusão de Curso de Graduação. Florianópolis: Udesc, 2008.

BAUMANN, Zygmund. Comunidade: a busca por segurança no mundo atual. Rio de Janeiro: Jorge Zahar, 2003.

BHABHA, Homi K. The Location of Culture. London: Routledge, 1994.

BINDER, Fernando Pereira. Bandas Militares no Brasil: difusão e organização entre

1808-1889. Dissertação de Mestrado. São Paulo: Unesp, 2006.

BRAH, Avtar \&t COOMBES, Annie (eds.) Hybridity and its Discontents: Politics, science, culture. London: Routledge, 2000.

CANCLINI, Néstor García. Hybrid Cultures: Strategies for Entering and Leaving Modernity. Minneapolis: University of Minnesota Press, 1995.

CAZARRÉ, Marcelo. A trajetória das danças de negros na literature pianistica brasileira: um estudo histórico-analítico. Pelotas: Ed. da Ufpel, 2001.

CLAYTON, Martin et al (eds.). The Cultural Study of Music: A Critical Introduction. New York and London: Routledge, 2003. CLIFFORD, James. Routes: Travel and Translation in the Late Twentieth Century. Cambridge: Harvard University Press, 1997. COOK, Nicholas \& EVERIST, Mark (eds.) Rethinking Music. Oxford: Oxford University Press, 2001.

FEATHERSTONE, Mike \& LASH, Scott M. (eds.) Spaces of Culture: City, Nation, World. London: Sage, 1999.

GEERTZ, Clifford. O saber local: novos ensaios em antropologia interpretativa. Petrópolis: Vozes, 1997.

HANNERZ, UIf. Scenarios for Peripheral Cultures. In Anthony King (ed.) Culture, Globalization and the World-System. London: Macmillan, 1991, p.107- 128.

HANNERZ, UIf. Fluxos, Fronteiras, Hibridos: palavras-chave da antropologia transnacional.

Mana 3(1), 1997, p.7-39.

HATTEN, Robert S. Interpreting musical gestures, topics, and tropes: Mozart, Beethoven, Schubert. Bloomington and Indianapolis: Indiana University Press, 2004.

HOBSBAWM, Eric \& RANGER, Terence (eds). The Invention of Tradition. Cambridge: Cambridge University Press, 1983.

HOOD, Mantle. The Challenge of Bi-musicality. Ethnomusicology, 4, 1960, p.55-59.

KERMAN, Joseph. Musicologia. São Paulo: Martins Fontes, 1987.

LATOUR, Bruno. Jamais fomos Modernos: Ensaios de Antropologia Simétrica. Rio de Janeiro: Editora 34, 1994.

LÉVI-STRAUSS, Claude. 0 Campo da Antropologia. In (do autor) Antropologia Estrutural Dois. Rio de Janeiro: Tempo Brasileiro, 1989, p.11-40.

LIMA, Edilson de. As Modinhas do Brasil. São Paulo: Edusp, 2001.

MACHADO, Cacá. O enigma do homem célebre: ambição e vocação de Ernesto Nazareth. São Paulo: Instituto Moreira Salles, 2007.

MAFFESOLI, Michel. O tempo das tribos: o declínio do individualismo na sociedade de massa. Rio de Janeiro : Forense Universitária, 1987.

MALM, Krister. A expansão dos direitos de propriedade intelectual e a música - uma área de tensão, in Samuel Araújo et al (eds) Música em Debate - perspectivas interdisciplinares. Rio de Janeiro: Mauad X/Faperj, 2008, p.87-98.

MCCLARY, Susan. The Blasphemy of Talking Politics during Bach Year. In Richard Leppert \& Susan McClary (eds.) Music and Society: The Politics of Composition, Performance and Reception. Cambridge: Cambridge University Press, 1987, p.13-62.

MONTEIRO, Maurício. A construção do gosto: música e sociedade na corte do Rio de Janeiro 1808-1821. São Paulo: Ateliê Editorial, 2008.

NEDERVEEN PIETERSE, Jan. Globalization as Hybridization. In Mike Featherstone et al (eds.) Global Modernities. London: Sage, 1995, p.45-68.

NEDERVEEN PIETERSE, Jan, Hybridity, So What? - The Antihybridity Backlash and the Riddles of Recognition. Theory, Culture \&t Society, 18, 23, 2001, p. 219-245. 
PIEDADE, Acácio \&t BASTOS, Marina. Análise de improvisações na música instrumental: em busca da retórica do jazz brasileiro. Revista Eletrônica de Musicologia, v.XI, 2007.

PIEDADE, Acácio \&t BENKE, Ester. Tópicas em Camargo Guarnieri: uma análise da Sonatina Nr. 1. Anais do XIX Congresso da ANPPOM. Curitiba, 2009.

PIEDADE, Acácio. Música Instrumental Brasileira e Fricção de Musicalidades. Antropologia em Primeira Mão, v.21, PPGAS/ UFSC, Florianópolis, 1997.

PIEDADE, Acácio. Brazilian Jazz and Friction of Musicalities. In E. Taylor Atkins (ed.) Planet Jazz. Jackson: University Press of Mississippi, 2003, p.41-58.

PIEDADE, Acácio. Jazz, música brasileira e fricção de musicalidades. Opus, v.11, 2005, p.113-123.

PIEDADE, Acácio. Expressão e sentido na música brasileira: retórica e análise musical. Revista Eletrônica de Musicologia, v.XI, 2007.

PIEDADE, Acácio. Tópicas em Villa-Lobos: o excesso bruto e puro. Anais do Simpósio Internacional Villa-Lobos. São Paulo, no prelo $(\mathrm{s} / \mathrm{d})$.

PIEDADE, Acácio. "Música Instrumental" In David Horn, Dave Laing \& John Shepherd (eds.) Encyclopedia of Popular Music of the World - Vol. IX, Genres of Caribbean and Central and South American Origin. New York - London: Continuum, 2010.

RATNER, Leonard G. Classic music: Expression, form, and style. New York: Schirmer Books, 1980.

RICOEUR, Paul. La mémoire, l'histoire, l'oubli. Paris: Éditions du Seuil, 2000.

STOBART, Henry (ed.). The New (Etnho)musicologies. Lanham: Scarecrow Press, 2008.

SUASSUNA, Ariano et al. 0 Nordeste e sua música. Estudos Avançados, vol.11, n.29, 1997, p.219-240.

VEIGA, Manoel. 0 estudo da modinha brasileira. Latin American Music Review,19,1,1998, p.47-91.

ZUMTHOR, Paul. Tradição e Esquecimento. São Paulo: Hucitec, 1997.

WERBNER, Pnina \& MODOOD, Tarig (eds.) Debating Cultural Hybridity: Multi-Cultural Identities and the Politics of AntiRacism. London: Zed Books, 1997.

WILLIAMS, Alastair. Constructing Musicology. London: Ashgate, 2007.

WOLFF, Christoph et al. "Bach". Grove Music Online/Oxford Music. Disponivel em http://www.oxfordmusiconline.com/ subscriber/article/grove/music/40023, acessado em 10/10/2010.

\section{Notas}

1 Para referências básicas no debate do hibridismo na atualidade, incluindo autores que criticam este conceito, ver BHABHA (1994), BRAH \& COOMBES (2000), CLIFFORD (1997), FEATHERSTONE \& LASH (1999), NEDERVEEN PIETERSE $(1995,2001)$ e WERBNER \& MODOOD (1997).

2 Compreensão no sentido de uma hermenêutica da cultura (Cf. GEERTZ, 1997).

3 Ver também a ideia de "tribos contemporâneas" (MAFFESOLI, 1987).

4 Tópicas são figuras de retórica. 0 termo é oriundo do conceito aristotélico topoï, parte do jargão filosófico dos estudos de Retórica. 0 que alguns musicólogos têm denominado topics envolve uma teoria analítica da expressividade e do sentido musical que se pode chamar de "teoria das tópicas" (RATNER,1980; AGAWU,1991; HATTEN;2004).0 universo estudado por estes autores é o da música europeia do período clássico e romântico. No entanto, creio que a teoria das tópicas é uma excelente via na compreensão da significação musical e da musicalidade em geral, sendo que sua adaptação para o âmbito da música brasileira é uma maneira fértil de lidar com o aspecto expressivo da musicalidade brasileira (ver PIEDADE, 2007).

5 LIMA (2001) traz partituras e análises de uma coleção de modinhas do século XVIII. Ali se pode encontrar diversas figurações de tópicas época-deouro que ainda hoje transitam pela música brasileira.

6 Como exemplos do estudo de tópicas na música de concerto, posso mencionar CAZARRÉ (2001), que estudou tópicas nas danças negras (batuques, sambas, jongos, lundus, etc), parte do repertório pianístico brasileiro desde 1850. Camargo Guarnieri emprega amplamente tópicas caipiras e épocade-ouro (PIEDADE \& BENCKE, 2009), e o estilo de Villa-Lobos tem como um de seus marcos as tópicas indígenas e ecológicas, além de um profundo idioma época-de-ouro (PIEDADE, s/d).

7 BINDER na verdade afirma que a formação das bandas é anterior à chegada da corte (2006, p.62).

8 A contrastividade é mesmo um fator fundante da própria identidade e etnicidade (BARTH, 1998).

Acácio Tadeu de C. Piedade é bacharel em Composição (UNICAMP), mestre e doutor em Antropologia (UFSC). Atualmente é professor associado do Departamento de Música e do Programa de Pós-Graduação em Música da Universidade do Estado de Santa Catarina (UDESC), onde ministra aulas de Análise Musical e Musicologia-Etnomusicologia. Suas pesquisas envolvem a análise musical e a música em seu contexto sócio-cultural e histórico. Suas publicações envolvem estudos sobre música indígena, música popular e erudita brasileira. 